\title{
Original Article \\ Knowledge and Skills on Triage among Nurses Working in Emergency Departments in Referral Hospitals in Rwanda
}

\author{
Innocent Twagirayezu ${ }^{1 *}$, Bhengu Busisiwe ${ }^{2}$, Emelyne Umutoni Cishahayo ${ }^{1}$ \\ ${ }^{1}$ General Nursing Department, School of Nursing and Midwifery, College of Medicine and Health Sciences, University of \\ Rwanda, Kigali, Rwanda \\ ${ }^{2}$ School of Nursing and Public Health, College of Health Sciences, University of KwaZulu-Natal, Durban, South Africa
}

*Corresponding author: Innocent Twagirayezu. General Nursing Department, School of Nursing and Midwifery, College of Medicine and Health Sciences, University of Rwanda, Kigali, Rwanda. Email: twagiracent@gmail.com.

\begin{abstract}
Background

Unpredictable numbers of patients attending emergency departments highlight the need for Triage. Triage which is the prioritization of patient care based on severity of illness or injury, prognosis, and availability of resources is effective when clinicians are knowledgeable and skilled to perform it.

\section{Objective}

To assess knowledge and skills on triage among nurses working in emergency departments of Rwandan referral hospitals.

\section{Methods}

Cross-sectional analytical design was adopted. ninety-six (96) nurses working in emergency departments were selected using proportionate stratified sampling method. Each hospital was considered as a stratum. A self-administered questionnaire and observation checklist were use as instruments. Inferential and descriptive statistics were used in analysis.

\section{Results}

The majority of participants (63.6\%) demonstrated low level of triage knowledge and almost a half $(47.9 \%)$ of participants had low level of triage skills. Nurses experience in emergency department, level of education and triage training were not found to significantly influence triage knowledge and skills positively $(\mathrm{P}>0.05)$.

\section{Conclusion}

Deficit in triage knowledge and skills were revealed among nurses working in emergency departments in Rwanda. Accredited continuous educational training on triage should be regularly provided to enhance knowledge and skills of emergency department nurses on Triage.

Rwanda J Med Health Sci 2021;4(3):398-405
\end{abstract}

Keywords: Triage, Emergency Department, Triage skills, triage knowledge

\section{Background}

Triage is considered as a basis of the organization of care in emergency departments (ED), and it is a term used to describe the prioritization of patient care based on severity of illness or injury, prognosis, and availability of resources. [1-3] Unpredictable numbers of patients attending emergency departments highlight the need of triage.[2] Triage ensures that resource distribution and timing of care is appropriate to the degree of patient's illness or injury.[3]
There are different nurse driven triage tools in use around the world which are professionally recognized and authenticated.[3] Where used these tools facilitate decision making structure and decreases biases in the triage decision making.[3] The scales are mostly used by many institutions and include Manchester Triage Scale, the Canadian Acuity Triage Scale and the Australian Triage Scale.[4-6] Due to the nature of patients attending emergency departments and what it takes to complete these scales, it is known that triage is done by well trained and experienced nurses ,[5] 
therefore the decision taken by a triage nurse is clearly influenced by his or her knowledge, skills and experience.[6] Unfortunately, nurse's knowledge and skills about triage is a serious concern.[1]

In evaluation for the application of the adopted South African Triage tool at Accident and Emergency Unit of University Teaching Hospital of Kigali (UTHK), it was revealed that none of the nurses used the tool as it should between 0 and 2 years of age.[8] However, this audit did not assessed nurses knowledge and skills on use of this tool.[8]

A study done in Spain reveals that perceived confidence while doing triage increases with triage training.[9] However, different studies show that nurses have limited training on triage. $[1,2,10-12]$ A cross sectional study done in Tanzania revealed that $78 \%$ emergency nurses were reported to be working without formal training in emergency nursing .[1] Likewise, findings from a study done in Ethiopia, Indonesia and China revealed that the level of education matters as it relates to knowledge and skills on triaging. $[3,4,12]$

In Rwanda, all district and provincial hospitals transfer their critically ill patients to referral hospitals. Nurses in emergency department first triage incoming patient for treatment priority, however, there is little to no studies in Rwanda showing if nurses have knowledge and skills to perform triage effectively. Therefore, this study intends to assess the knowledge and skills of nurses working in emergency departments in Rwanda referral hospitals.

\section{Method}

\section{Study setting}

This study was conducted at four Referral Hospitals, namely, University Teaching Hospital of Kigali (UTHK), University Teaching Hospital of Butare (UTHB), Rwanda Military Hospital $(\mathrm{RMH})$ and King Faisal Hospital (KFH).

\section{Design}

A descriptive cross-sectional design was used to assess knowledge and skills on triage among nurses working in Emergency Departments from February 2019 to April 2019.

\section{Population}

The study population were 131 Nurses working in Emergency Department (ED) from the four mentioned referral hospitals, because UTHK has 60 nurses working in emergency department, RMH has 32 nurses, UTHB has 21 and KFH has 18. Only nurses working in ED with more than 6 months of experience and who consented to participate voluntarily were included in the study. Experienced nurses in ED who refuse to participate and other clinician were excluded in the study.

\section{Sampling}

A sample of 96 nurses who had experience of more than 6 months working in emergency department was selected from the sampling frame of 131 nurses. a proportionate stratified sampling was used. Each hospital was a stratum and the sample was a proportion from each stratum from the total study population. A blind random selection was used to select participants from each stratum. The size of the sample was obtained from the use of Taro Yamane [13] Formula which considers a 95\% of confidence interval and 0.05 of margin error.[13]

\section{Data collection tool}

The study used a self-administered questionnaire and observational check list developed by Aloyce [2] to assess knowledge and skills of nurses working in emergency department . Permission to use the tool was secured from the corresponding author via email.[2] The tool consisted of 4 sections: Section 1 entailed demographic characteristics of the participants. Section 2 had 10 questions on triage knowledge, Section 3 a Likert self-assessment tool designed to assess triage perceived skills and, section 4 observation checklist designed to assess triage skills by the researcher.

\section{Measure}

The triage knowledge questionnaire had 1 question asking triage definition, 1 question with 4 sub questions on triage knowledge about time wait limit in ED and structured case scenarios of 8 items assessing triage knowledge on patient categorization. Correct responses were awarded 1 mark and incorrect 0 . Section 3 of the questionnaire is a Likert self-assessment tool designed to assess triage perceived skills ranging from "very good" with 5 points, "good" with 4 point, "fair" with 3 points, "poor" with 2 points and "need improvement" with 1 point.

Mean percentage scores were used to categorise knowledge into three levels according the McDonald's standard learning outcome measured criteria for categorizing knowledge and skills ,[14] which includes low $(<60 \%)$, moderate (60$79.9 \%$ ), high (80 to $100 \%$ ). 
The observational checklist designed to assess triage skills had twenty-two (22) items observed with yes or no responses.

\section{Data Collection}

Participants were approached in their work stations per appointment, given explanation and requested to contribute in the study. Those who granted consent to participate in the study signed the consent forms and were updated on the process of data collection. The questionnaire was distributed to the participants after observation process which took between 60 to 120 minutes unanimously. Observation was done by the researcher by observing the participants while they perform triage. To avoid Hawthorne effect in the study [15], time for the observation was not communicated. Output from participants were kept strictly confidential. Four nurses from another institution were trained on data collection tools and process by the Researcher and were recruited as Research Assistants. The questionnaire was designed in English as all the participants' language of instruction is English.

\section{Data analysis}

Data collected were analyzed descriptively, where frequency distribution and percentages were described. Chi-square and Fishers exact test were used to assess the relationship between different socio-demographic variables with triage knowledge and skills. The statistical significance of P-value $<0.05$ was considered. This analysis was done by the use of Statistical Package for Social Science (SPSS) Version 22.

\section{Ethical Consideration}

Ethical clearance from IRB/CMHS and permission for data collection was secured from all selected study settings. Prior to data collection, all participants were guaranteed the right to withdraw from the study at any time with no negative consequence. Research objectives, processes and rights concerning the study were also explained to participants. The ethical principle of fairness or justice was observed through random sampling so that any of the nurses stood a chance to participate. The researcher acquired permission from the participants through consent form signing including permission to be observed while triaging patients practically. To ensure anonymity and confidentiality, codes were used on questionnaires which were finally kept in a locked box with soft copies kept confidential in a computer accessible with a password known by the researcher only.

\section{Result}

\section{Demographic characteristics of the} participants

A response rate of $96.7 \%$ was obtained. The sociodemographic variables of the 96 participants were presented in table1. The majority of participants $(56 \%)$ were female in the age group of 24-34 years (63.5\%). Fiftyeight $(58.3 \%)$ of the participants had advanced diploma in nursing sciences. More than fiftynine percent $(59.4 \%)$ of participant stipulated to be trained on triage. Only $33.3 \%$ of nurses had experience of more than 5 years in emergency department.

\section{Table 1. Demographic characteristics of the participants}

\begin{tabular}{ll}
\hline Demographics & N (\%) \\
\hline Age & $61(63.5)$ \\
$25-34$ & $33(34.4)$ \\
$35-44$ & $2(2.1)$ \\
Above 44 & \\
Gender & $42(43.7)$ \\
Male & $54(56.3)$ \\
Female & \\
Level of Education & $56(58.3)$ \\
Advanced diploma (A1) & $37(38.6)$ \\
Bachelor degree (A0) & $3(3.1)$ \\
Masters in Nursing & \\
Work experience in & \\
Emergency Department & \\
6 Months-1 Year & $19(19.8)$ \\
1-3 Year & $19(19.8)$ \\
3-5 Years & $26(27.1)$ \\
Above 5 years & $32(33.3)$ \\
\hline
\end{tabular}

Participant Knowledge on Triage

The series of questions were asked with regard to participant knowledge on triage. To obtain knowledge score each correct responses were summed up. Basing on McDonald's standard learning outcome measured criteria [14] for categorizing knowledge we found that the majority $(63.6 \%)$ had low level of triage knowledge, $20.8 \%$ of participants had moderate level and only $15.6 \%$ had high knowledge on triage. Figure .1 below 


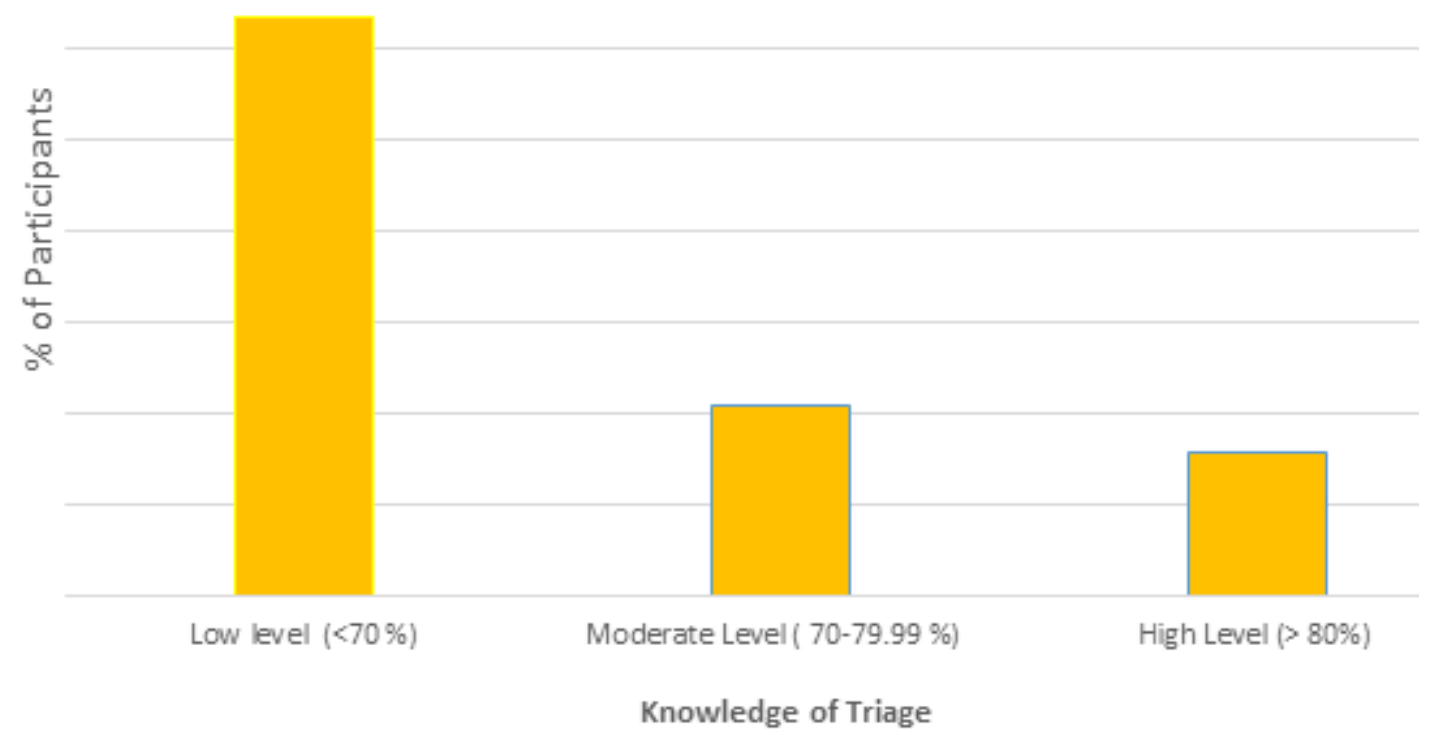

Fig 1. Participants' levels of knowledge on triage $(N=96)$

In the analysis of the association between Triage knowledge and selected demographic variable, the Pearson chi-square test was calculated and revealed that the level of nursing education, triage training, experience in emergency department were not statistically associated with level of triage knowledge ( $p>0.05)$. See Table 2 describing association between triage knowledge and demographic variables.

Table 2. Association between demographic characteristics and level of triage knowledge

\begin{tabular}{lllll}
\multicolumn{4}{c}{ Level of triage knowledge } & \\
\hline Low level & Moderate & High level & Total & p- value \\
of triage & $\begin{array}{l}\text { level of } \\
\text { triage } \\
\text { knowledge }\end{array}$ & $\begin{array}{l}\text { of triage } \\
\text { knowledge }\end{array}$ & N (\%) & \\
$\mathbf{N}(\%)$ & knowledge & N (\%) & \\
& $N(\%)$ & & \\
\hline
\end{tabular}

\begin{tabular}{|c|c|c|c|c|c|}
\hline \multicolumn{6}{|l|}{ Age } \\
\hline $25-34$ & $40(65.6)$ & $11(18)$ & $10(16.4)$ & $61(100)$ & \multirow[t]{3}{*}{.789} \\
\hline $35-44$ & $20\left(60^{\circ} .6\right)$ & $8(24.2)$ & $5(15.2)$ & $33(100)$ & \\
\hline$<45$ & $1(50)$ & $1(50)$ & $0(0)$ & $2(100)$ & \\
\hline \multicolumn{6}{|l|}{ Gender } \\
\hline Male & $28(66.7)$ & $8(19)$ & $6(14.3)$ & $42(100)$ & \multirow[t]{2}{*}{.854} \\
\hline Female & $33(61.1)$ & $12(22.2)$ & $9(16.7)$ & $54(100)$ & \\
\hline \multicolumn{6}{|c|}{ Level of education } \\
\hline A1 & $35(63.6)$ & $11(20)$ & $9(16.4)$ & $55(100)$ & \multirow[t]{3}{*}{.094} \\
\hline AO & $6(68.4)$ & $(21.1)$ & $(10.5)$ & $38(100)$ & \\
\hline Masters & $0(0)$ & $1(33.3)$ & $2(66.7)$ & $3(100)$ & \\
\hline \multicolumn{6}{|l|}{$\begin{array}{l}\text { ED experi- } \\
\text { ence }\end{array}$} \\
\hline$<1$ year & $14(73.7)$ & $2(10.5)$ & $3(15.8)$ & 19(100) & \multirow[t]{4}{*}{.129} \\
\hline 1-3 Year & $12(63.2)$ & $5(26.3)$ & $2(10.5)$ & $19(100)$ & \\
\hline 3-5 Years & $13(50)$ & $5(19.2)$ & $8(30.8)$ & $26(100)$ & \\
\hline$>5$ Years & $22(68.7)$ & $8(25)$ & $2(6.3)$ & $32(100)$ & \\
\hline \multicolumn{6}{|c|}{ Triage training } \\
\hline Trained & 37 (64.9) & $11(19.3)$ & $9(15.8)$ & 57 (100) & \multirow[t]{3}{*}{.903} \\
\hline Not trained & $24(61.5)$ & $9(23.1)$ & $6(15.4)$ & $39(100)$ & \\
\hline Total & $61(63.6)$ & $20(20.8)$ & $15(15.6)$ & $96(100.0)$ & \\
\hline
\end{tabular}




\section{Triage skills}

Regarding to triage skills; participants perceived and observed skills on triage were considered. On observation. Almost all of the participants $(99.0 \%)$ assessed patient airways while $85(88.5 \%)$ assessed respiratory status. Three quarters of participants $(75.5 \%)$ did not assess capillary refill and the majority $(87.5 \%)$ did not assess whether the patients' skins were cold or hot which can affect right patient categorization. Surprisingly, $92.7 \%$ were able to categorize the patient in the right category. In addition, all participants $(100.0 \%)$ were able to allocate the patient in the right place in ED. Table 3 below shows observed triage skills in frequencies and percentages.

Table 3. Summary statistics of Observed triage skills ( $N=96)$

\begin{tabular}{|c|c|c|c|}
\hline Item & $\begin{array}{l}\text { Yes } \\
\text { n (\%) }\end{array}$ & $\begin{array}{l}\text { No } \\
\text { n (\%) }\end{array}$ & $\begin{array}{l}\text { Total } \\
\text { n (\%) }\end{array}$ \\
\hline Nurse assigned for patients' triage & $96(100.0)$ & $0(0.0)$ & $96(100.0)$ \\
\hline $\begin{array}{l}\text { Does the nurse actually triage the pa- } \\
\text { tients }\end{array}$ & $95(99.0)$ & $1(1.0)$ & $96(100.0)$ \\
\hline Air way assessment & $94(97.8)$ & $2(2.1)$ & $96(100.0)$ \\
\hline Respiratory status assessment & 85 (88.5) & $11(11.5)$ & 96 (100.0) \\
\hline Circulatory status assessment & $91(94.8)$ & $5(5.2)$ & $96(100.0)$ \\
\hline Assess for chest movement & $62(64.6)$ & $34(35.4$ & $96(100.0)$ \\
\hline Assess for breath sound & $1(1.0)$ & 95(99.0) & $96(100.0)$ \\
\hline Assess breathing pattern & $10(10.4)$ & $86(89.6)$ & 96 (100.0) \\
\hline Assess blood pressure & $95(99.0)$ & $1(1.0)$ & $96(100.0)$ \\
\hline Assess pulse rate & 90(93.7) & $6(6.3)$ & 96 (100.0) \\
\hline $\begin{array}{l}\text { Assess for skin/mucous membrane color } \\
\text { (pink, pale) }\end{array}$ & $31(32.3)$ & $65(67.7)$ & $96(100.0)$ \\
\hline $\begin{array}{l}\text { Assess for skin temperature (warm, hot, } \\
\text { cool/cold) }\end{array}$ & $12(12.5)$ & $84(87.5)$ & $96(100.0)$ \\
\hline Assess for capillary refill & $24(25.0)$ & $72(75.0)$ & 96 (100.0) \\
\hline Temperature measurement & $91(94.8)$ & $5(5.2)$ & $96(100.0)$ \\
\hline Pain assessment & $79(82.3)$ & $17(17.7)$ & 96 (100.0) \\
\hline $\begin{array}{l}\text { Neurological assessment: Alert, responds } \\
\text { to voice, responds to pain, Unresponsive. }\end{array}$ & $94(97.9)$ & $2(2.1)$ & $96(100.0)$ \\
\hline Triage documentation & $91(94.8)$ & $5(5.2)$ & 96 (100.0) \\
\hline $\begin{array}{l}\text { Re-assessment on regular basis of those } \\
\text { patients who are waiting done to see if } \\
\text { their conditions have deteriorated and } \\
\text { need to be seen more urgently? }\end{array}$ & $68(70.8)$ & $28(29.1)$ & 96 (100.0) \\
\hline $\begin{array}{l}\text { Nurse categorize the patient according to } \\
\text { triage categorization? }\end{array}$ & $89(92.7)$ & $7(7.3)$ & $96(100.0)$ \\
\hline $\begin{array}{l}\text { Nurse initiate nursing intervention } \\
\text { during triage categorization? }\end{array}$ & $78(81.2)$ & $18(18.8)$ & 96 (100.0) \\
\hline $\begin{array}{l}\text { Nurse allocate the patient in the right } \\
\text { place? }\end{array}$ & 96 (100.0) & $0(0.0)$ & $96(100.0)$ \\
\hline $\begin{array}{l}\text { Allocate the patient by collaboration with } \\
\text { other emergency or medical doctor effec- } \\
\text { tively? }\end{array}$ & $88(91.7)$ & $8(83)$ & $96(100.0)$ \\
\hline
\end{tabular}




\section{Distribution of participants according to level of Perceived Triage Skills}

Basing on McDonald's standard learning outcome measured criteria for categorizing skills, we have found that nearly half of participants $(47.9 \%)$ had low level of triage skills, while $45.8 \%$ had moderate level of skills and only $6.3 \%$ had high level of triage skills. (See Figure 2).

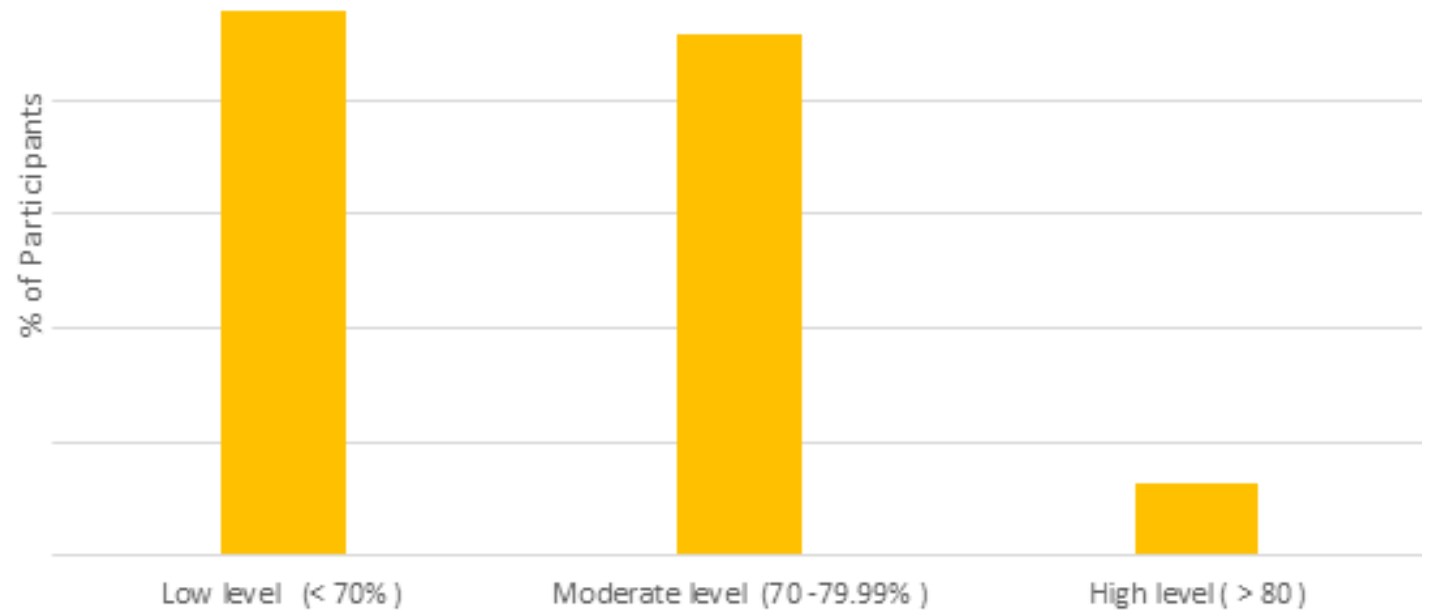

Fig 2. Participants' levels of triage skills ( $N=96)$

Analyzing the association of perceived triage skills and demographic characteristics, we have found that age, sex, level of education, experience in ED,

Table 4. Association between demographic characteristics and observed triage skills and triage training were not statistically associated with the level of perceived triage skills. $(\mathrm{P}>0.05)$. (Table 4)

\section{Level of triage knowledge}

\begin{tabular}{|c|c|c|c|c|c|}
\hline $\begin{array}{l}\text { De mographic } \\
\text { characteristics }\end{array}$ & $\begin{array}{l}\text { Low level of } \\
\text { triage skills }\end{array}$ & $\begin{array}{l}\text { Moderate level } \\
\text { of triage skills }\end{array}$ & $\begin{array}{l}\text { High } \\
\text { level of } \\
\text { triage } \\
\text { skills }\end{array}$ & $\begin{array}{l}\text { Total } \\
\text { N (\%) }\end{array}$ & $\begin{array}{l}\mathbf{P} \\
\text { Value }\end{array}$ \\
\hline \multicolumn{6}{|l|}{ Age } \\
\hline $25-34$ & $28(45.9)$ & $28(45.9)$ & $5(8.2)$ & $61(100)$ & \multirow{3}{*}{0.394} \\
\hline $35-44$ & $17(51.5)$ & $15(45.5)$ & $1(3)$ & $33(100)$ & \\
\hline$<45$ & $1(50)$ & $1(50)$ & $0(0)$ & $2(100)$ & \\
\hline \multicolumn{6}{|l|}{ Gender } \\
\hline Male & $18(42.9)$ & $21(50)$ & $3(7.1)$ & $42(100)$ & \multirow{2}{*}{0.678} \\
\hline Female & $28(51.8)$ & $23(42.6)$ & $3(5.6)$ & $54(100)$ & \\
\hline \multicolumn{6}{|c|}{ Level of education } \\
\hline A1 & $27(14.5)$ & $24(78.2)$ & $4(7.3)$ & $55(100)$ & \multirow{3}{*}{0.506} \\
\hline A0 & $18(15.8)$ & $18(78.9)$ & $2(5.3)$ & $38(100)$ & \\
\hline Masters & $1(33.3)$ & $2(66.7)$ & $0(0)$ & $3(100)$ & \\
\hline \multicolumn{6}{|l|}{ ED experience } \\
\hline Below 1 year & $9(47.4)$ & $9(47.4)$ & $1(5.2)$ & $19(100)$ & \multirow[b]{4}{*}{0.689} \\
\hline 1-3 Year & $11(58)$ & $7(36.8)$ & $1(5.2)$ & $19(100)$ & \\
\hline 3-5 Years & $13(50)$ & $10(38.5)$ & $3(11.5)$ & $26(100)$ & \\
\hline Above 5Years & $13(40.6)$ & $18(56.3)$ & $1(3.1)$ & $32(100)$ & \\
\hline \multicolumn{6}{|l|}{ Triage training } \\
\hline Trained & $27(47.4)$ & $26(45.6)$ & $4(7)$ & $57(59.4)$ & \multirow{2}{*}{0.093} \\
\hline Not trained & $19(48.7)$ & $18(46.2)$ & $2(5.1)$ & $39(40.6)$ & \\
\hline
\end{tabular}




\section{Discussion}

The results obtained indicated that $(56 \%)$ of the surveyed participants were female and that 58.3\% had diploma in nursing (A1). This is equivalent with studies done in Ethiopia and Switzerland. $[8,9]$ A cross sectional study done in Tanzania revealed that $78 \%$ emergency nurses were reported to be working without formal training in emergency nursing the fact that differ with findings of the current study which found out that $40.6 \%$ had no triage training. [1]. Difference lie in the methodology used and sample size. With regard to level of education, in the current study only $3.1 \%$ of the surveyed nurses had master of science in nursing, this is somehow congruent with what of a similar study done in China $1 \%$ and slightly differ with what of a study done in Ethiopia 6.9\%. [4,16] this shows that training nurses at high level is still needed especially in the developing countries.

The present study result discovered that 33.3\% $(n=32)$ had experience in emergency department of more than 5 years. Meaning that majority of the surveyed nurses had no experience in ED. This is a fact that can hinder hands on skills on triage. This study outcome was congruent with what of a similar study done in Ghana which found that $24.6 \%$ were working in ED with limited experience but contrary to a study done in Nigeria $61 \% .[5,10]$ In addition, the study revealed that majority of the participants $(63 \%)$ had low knowledge on triage. This indicates that no matter how emergency departments of Rwandan referral hospitals are structured; triage is still performed by nurses with limited educational preparation and knowledge to respond to the overcrowded patients in ED. This discrepancy was also highlighted in studies done in different African counties. $[1,8,10]$ In India, $62 \%$ of participants were revealed to have moderate level of triage knowledge, the fact that is incongruent with the current study. [11] This is probably due to difference in sample size and the reference scale criteria used. The deficit in triage knowledge is explained by the lack of triage training. The current study found that $40.6 \%$ had no triage training. It was revealed by MartinezSegura et al that perceived confidence while doing triage increases with triage training [12] therefore having almost half of participants without triage training in the current study, probably explains why more than a half (63.6\%) of participants had low level of triage knowledge. In this study, the mean triage skills score was $69.3 \%$ and almost half of participants $(45.8 \%)$ had moderate triage skills. This is congruent with a similar study done in Nigeria where $51.6 \%$ had moderate triage skill. [10]
However, results are contrary to findings from a previous descriptive cross-sectional study done in Ethiopia. $[9,10]$ This is probably due to difference in questionnaire used and sample size. Considering the mean triage skills score which was 69.32 , findings were similar to those of a study done in Indonesia that found the mean score of triage skills of 75.1 with SD of 11.2.[13] In the course of data collection, the researcher observed that $91.7 \%$ of participants allocated patients by collaboration with other emergency personnel or medical doctor. This explains that collaboration may help nurses to have a triage skill for precise decisions under certain circumstances. Additionally, having 63.8\% with low level of triage knowledge explains why only $45.8 \%$ had moderate level of triage skills because studies done in Indonesia and Ethiopia have demonstrated that triage knowledge were statistically correlated with triage skills. $(r=.38$, $\mathrm{p}<.01)$ and $(\mathrm{r}=.68, \mathrm{p} .01)$ respectively. $[2,13]$

\section{Limitation}

The study did not obtain $100 \%$ of responses due to exclusion criteria because we obtained a response of $96.8 \%$. This decreases the statistical power of results and therefore we cannot generalize findings to all nurses working in ED.

\section{Conclusion and Recommendation}

Findings reflect that nurses working in emergency department of referral hospitals in Rwanda has low level of triage knowledge and skills. No factor was found to be significantly associated with either triage knowledge or skills. These results then imply that nurses working in ED be provided with regular training related to triage in the form of continuous development programs, so that they become equipped with required knowledge and skills to do triage. Findings also call for nursing schools to make sure that the curriculum provides the student nurses with competencies required to do triage including mass causality triage effectively in all programs. We recommend also similar study in all district hospitals since triage system is now applies in all Hospitals.

\section{Conflict of interest}

There is no conflict of interest

\section{Acknowledgment}

We acknowledge the support provided by the University of Rwanda and all our participants for availing themselves for the realization of this manuscript. 
This article is published open access under the Creative Commons Attribution-NonCommercial NoDerivatives (CC BYNC-ND4.0). People can copy and redistribute the article only for noncommercial purposes and as long as they give appropriate credit to the authors. They cannot distribute any modified material obtained by remixing, transforming or building upon this article. See https:// creativecommons.org/licenses/by-nc-nd/4.0/

\section{References}

1. Afaya A, Azongo TB, Yakong VN. Perceptions and Knowledge on Triage of Nurses Workingin Emergency Departments of Hospitals in the Tamale Metropolis . IOSR J Nurs Heal Sci. 2017;6(3):59-65.

2. Aloyce $\mathrm{R}$, Leshabari $\mathrm{S}$, Brysiewicz $\mathrm{P}$. Assessment of knowledge and skills of triage amongst nurses working in the emergency centres in Dar es Salaam, Tanzania. African $J$ Emerg Med [Internet]. 2014;4(1):14-8. Available from: http://dx.doi.org/10.1016/j. afjem.2013.04.009

3. Kerie S, Tilahun A, Mandesh A. Triage skill and associated factors among emergency nurses in Addis Ababa, Ethiopia 2017: a cross - sectional study. BMC Res Notes [Internet]. 2018;11(658):4-9. Available from: https://doi.org/10.1186/s13104-018-37698

4. Hammad K, Peng L, Anikeeva O, Arbon P, Du $\mathrm{H}$, Li Y. Emergency nurses' knowledge and experience with the triage process in Hunan Province, China. International Emergency Nursing. 2017;25-9.

5. Steiner D, Renetseder F, Kutz A, Haubitz S, Faessler L, Anderson JB, et al. Performance of the manchester triage system in adult medical patients. A prospective cohort study. $J$ Emerg Med [Internet]. 2016;50(4):678-89. Available from: http://dx.doi.org/10.1016/j. jemermed.2015.09.008

6. Jordi K, Grossmann F, Gaddis GM, Cignacco E, Denhaerynck K, Schwendimann R, et al. Nurses ' accuracy and self-perceived ability using the Emergency Severity Index triage tool: a cross-sectional study in four Swiss hospitals. Scand J Trauma Resusc Emerg Med [Internet]. 2015;23(62):1-10. Available from: http: / / dx.doi.org/ 10.1186/s13049-0150142-y

7. Pouraghaei M, Sadegh Tabrizi J, Moharamzadeh P, Rajaei Ghafori R, Rahmani F, Najafi Mirfakhraei B. The Effect of Start Triage Education on Knowledge and Practice of Emergency Medical Technicians in Disasters. $J$ Caring Sci [Internet]. 2017;6(2):119-25. Available from: http://journals.tbzmed.ac.ir/ JCS/Abstract/JCS_3927_20160413232353
8. Niwenkunda J, Uwineza C, Mukakamali $\mathrm{CD}$, Byiringiro J-C, Tsuchiya J, Lukas S. Evaluation of Accident and Emergency Triage at a University Teaching Hospital in Kigali, Rwanda. Rwanda $J$ Ser $F$ [Internet]. 2015;2(2):4314. Available from: http://search.ebscohost.com/ login .aspx?direct $=$ true $\& d b=a w n \& A N=r j-$ 125994\&site=ehost-live\%0Ahttp: / / www . ajol.info/index.php/rj/article/view/ 125994

9. Martinez-segura E, Martínez-segura E, Lleixà-fortuño M, Salvadó-usach T, Solàmiravete $\mathrm{E}$. Competence of triage nurses in hospital emergency. Emergencias. 2017;(29):173-7.

10.Al MA, Rn K, Dnsc EB, Emeritus C, Alasad JA. Jordanian nurses ' perceptions of their preparedness for disaster management. Int Emerg Nurs [Internet]. 2012;20(1):14-23. Available from: http:/ /dx.doi.org/10.1016/j. ienj.2011.01.001

11.Innes K, Plummer V, Considine J. Nurses ' perceptions of their preparation for triage. Australas Emerg Nurs J. 2011;14:81-6.

12. Fathoni M, Sangchan H, Ph D, Songwathana $\mathrm{P}, \mathrm{Ph}$ D. Relationships between Triage Knowledge, Training, Working Experiences and Triage Skills among Emergency Nurses in East Java, Indonesia. Nurse Media J Nurs. 2013;3(1):511-25.

13. Adam AM. Sample Size Determination in Survey Research. $J$ Sci Res Reports. 2020;26(6):90-7.

14. McDonald RP, Ho MHR. Principles and practice in reporting structural equation analyses. Psychol Methods. 2002;7(1):64-82.

15. Sedgwick P, Greenwood N. Understanding the hawthorne effect. BMJ. 2015;351(September):1-2.

16. Duko B, Geja E, Oltaye Z, Belayneh F, Kedir A, Gebire M. Triage knowledge and skills among nurses in emergency units of Specialized Hospital in Hawassa, Ethiopia : cross sectional study. BMC Res Notes [Internet]. 2019;12(21):1-4. Available from: https://doi.org/10.1186/s13104-0194062-1

17. Lola N, Abdulraheem A, Ahmadu I, Kever RT, Gagare AA, Abore FM. Assessment of Knowledge, Skills and Preparedness of Nurses on Management of Mass Casualty in University of Maiduguri Teaching Hospital. Int J Nurs Heal Sci. 2016;3(6):48-52.

18. Manoharan M, Ravindran V, Ranjini K, Jacob E, Johnson MA, Nayak R. Knowledge on Triaging among Pediatric Nurses in Pediatric Emergency Services ( PES ). IOSR $J$ Nurs Heal Sci. 2018;7(1):1-5. 